\title{
Web Service Negotiation Using AHP for Business Oriented Design of Service Level Agreements
}

\author{
${ }^{1}$ Mr. R. Raju, ${ }^{2}$ Ms. D. Dhivya, ${ }^{3}$ Ms. R.Saranya, ${ }^{4}$ Ms. S. I. Abbinaya \\ ${ }^{1}$ Associate Professor and Head, IT Dept, Sri Manakula Vinayagar Engineering College, Pondicherry-605104. \\ rajupdy@gmail.com \\ 2,3,4 Dept Of Information Technology, Sri Manakula Vinayagar Engineering College, Pondicherry-605104. \\ dhivya.blu@gmail.com \\ rsaranya.kavya@gmail.com \\ saiabbinaya333@gmail.com
}

\begin{abstract}
The service purchaser needs to stipulate for the service. The service contributor will afford the service to the purchaser. The powerful use of services to assemble business processes in service computing pressures that the Quality of Services (QoS) convene consumers' perspective. When manipulating the services, a service provider must set apart the quality of service levels that will be existing to the customers. Programmed web-based negotiation of Service Level Agreements (SLA) can assist in describing the QoS necessities of critical service-based processes. We put forward a trusted Negotiation Organizer(NO) structure that performs adaptive and intelligent mutual bargaining of SLAs between a service contributor and a service purchaser based on each party's elevated level business necessities. We also define an algorithm for adapting the decision functions during an continuing negotiation to match with an opponent's offers or with simplified purchaser preferences. The NO uses intelligent agents to conduct the negotiation locally by choosing the most suitable multi criteria decision making system known as Analytic Hierarchy Process (AHP).
\end{abstract}

Index Terms -Quality of services, service-level agreement, negotiation, intelligent agents, adaptive negotiation, web services, Analytic Hierarchy Process, Multi-criteria decision making.

\section{INTRODUCTION}

The expansion of web technologies, helps to provide the resourceful online negotiation system for e-business. Many researches are conceded out to confirm that automated negotiation system is important in Service Oriented Architecture(SOA). In SOA the negotiation is carried out through the Service Level Agreement (SLA) between the service constructor and service purchaser. Negotiation is planned in order to make sure that there is no discrepancy between the service provider and consumer in attainment of an agreement. The SLA script contains information about the parties involved in the negotiation, time period over which the SLA is valid, level of services that both the parties agree on, penalties for not gathering the specified service, specification of what is not enclosed in SLA, and so on. Business people recognize with the service idea because it is a basic method by which typical business associations are arranged and executed. The negotiation of a SLA between service donor and service customer is usually based on a SLA pattern. A pattern defines factor ranges of certain service features which are supported by the service donor. In the simplest crate, there are no factor options for the service customer, and he can either accept the given offer or reject it. More multifaceted negotiations are feasible, and described in the WS-Agreement design.

An SLA is an arrangement between the service donor and the service customer concerning the guarantee of delivered services. It describes general understandings and expectations of a service between the two parties. The service guarantees concern the operations to be executed and the QoS level to be delivered. Service Level Agreement have been used in area such telecommunication, for several years. The SLA article include information about the parties involved in the negotiation, time period over which the SLA is legal. The negotiation techniques such as game theory, time based decision making functions, machine learning, genetic algorithm, intelligent agents etc have been used. In sight of the consequence of a rapid, effortless, and useful negotiation service for the emerging service cloud, we propose an negotiation service provisioning system for web services SLAs using Analytic Hierarchy Process(AHP) .

Using AHP we address the problem of delivering the determinant service based on the preferences gained from the service customer. Multimedia (MM) applications such as video-on-demand and teleconferencing offer services with altered quality of service (QoS) requirements. Hence, the user should be able to negotiate the required QoS depending on needs, the end-system characteristics and financial power. In reply to a service demand with the desired QoS, most QoS negotiation approaches return an recognition or a simple refutation of the request. Negotiation move towards the practice of contact rule policies and discovery based on negotiation matching parts' trust value, which is the value of attribute Trust Degree of the trust record. At some stage in negotiation, the system will get the values of Trust degree repeatedly and select the rule control policies animatedly. The Adaptive system has no trust documentation, the system will give the user a non-payment level of trust that is the preliminary trust.

The preliminary trust means that the user neither been trusted nor not been trusted. Negotiation tactic is a dynamic negotiation tactic. It is a balance of eager tactic and economical tactic, and it makes Adaptive system has a high security level.AHP deals with three primary functions such as, structuring complexity, measurement, and synthesis helps in understanding why AHP is such a general methodology with such a wide variety of applications. Service-Oriented Architecture (SOA) is an innovative computing podium that is being adopted world-wide and has earned the shore up of every key software donor. SOA has obtained popularity due to Web Services. Dynamic discovery is an significant piece of 
SOA. Basically, SOA is poised of three interior pieces: service donor, service customers, and the registry service. The role of donors and customers are noticeable, but the role of the registry service needs some elucidation. The registry service is an agent between donors and customers. Stakeholder's intention is to resolve whether predefined type and quality attributes of services are met. Negotiation is conceded out between the service donor and the customer before any kind of contracts can be recognized. This negotiation is to raise divergences because of difference in Quality of Service (QoS).The service agreement disquiet the operations to be executed and the QoS level to be conveyed. Rest of the paper is organized as follows: Section II deals with the prior research related to service negotiation and AHP, Section III is about the Analytic Hierarchy Process, Section IV describes the system architecture ,Section V explains the working model of the AHP.

\section{RELATED WORK}

The related work enhance the service negotiation between service customer and service donor. Service customer will request for the particular service. service donors can grant several service types and different levels of service[4]. This approach employ an iterative tradeoff mechanism for evaluating opponent's offers and generating counteroffers of mutual gain based on selected quality of service parameters[8]. This paper[6] present a protocol for service level negotiation which uses web service and includes both quality of service and security for negotiation purpose. In this paper[9] a situated decision support system for efficient negotiating of service level agreements (SLAs) in Grids. Situated decision support systems effectively combine human judgment with autonomous decision making and action by agents. Service Level Agreements (SLAs) play a major role in ensuring the quality of Service Based System(SBSs)[1]. In our previous model a time-based decision making system is used. In this paper we propose a multi-criteria decision making system using Analytical Hierarchy Process(AHP).Using analytical hierarchy process, decision are taken from the criteria, sub-criteria and alternatives. Analytical hierarchy process based on three criteria Information Security, Interoperability \& High Availability[10].

To accomplish our goal we have presented the problem as hierarchy, established the priorities, criteria and performed mathematical computing to prove our analysis. An enhanced ranking approach to AHP alternatives based on variable weights is given by the way of constructing a variant analysis structure of AHP evaluating problems and its corresponding value system for evaluating alternatives[11].This paper[12] reflect the preference of decision maker, AHP method was utilized to build the preference cone. Thus it illustrates the availability and efficiency of the hybrid model. In paper[13] a new decision making method was presented based on outranking relation and AHP. In paper[14], the decision criteria under interval probabilities are combination, marginalization, condition, Bayesian inferences are identified. In paper[15] By using AHP, complicated decision system is structured, weightiness of the connection factor is compared, validity model is formed, and quantitative basis for decision and analysis is provided. Multiple services are used in Multicriteria decision making system. As a result a better service has been chosen from multiple service and it should be returned to the consumer.

\section{RESEARCH PROPOSAL}

Analytic Hierarchy Process (AHP) is one of the Multi Criteria decision making methods that were formerly developed by Prof. Thomas L. Saaty. Service negotiation is an central activity in web service after all the services has been configured and poised. Service negotiation is purely based on decision making. This is the reason why we show up Analytic Hierarchy Process (AHP) in our project. AHP deals with numerous large, vibrant and difficult real world problems. The advantages of AHP over other multi criteria methods are its suppleness, impulsive appeal to the decision makers and its capability to test the inconsistencies. In general, users find the pair wise comparison form of data input as clear-cut and suitable AHP method has the distinct feature, in that it decomposes a decision problem into its element parts and builds hierarchies of criteria. At this point the importance of each element (criterion) becomes clear. AHP exclusively will face difficulties to work out the interactive troubles. The sample graphical representation of AHP for choosing the efficient service with non-functional quality attribute is given below:

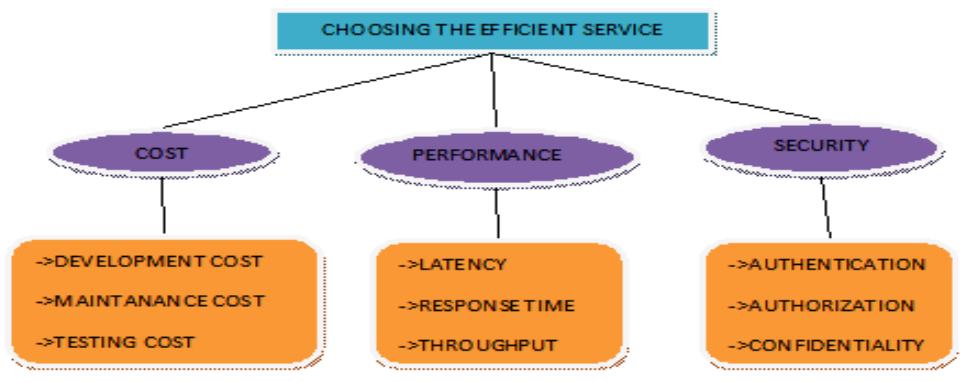

Fig. 1. Sample Graphical Representation for AHP

AHP also has the capacity to transform qualitative parameters into quantitative results. To route the preferences of an individual or group in decision making is the main mathematical objective of the AHP. Primarily, the AHP facilitates the method of rising priorities for alternatives and the criteria used to judge the alternatives. Initially, in order to achieve the goal priorities are derived for the criteria and then priorities are derived for the performance of the alternatives on each criterion. Based on pair-wise assessments using judgments these priorities are derived or ratios of measurements from a 
scale if one exists. At last, a weighting and adding process is used to attain overall priorities for the alternatives. In a nutshell, the AHP is a valuable procedure for discerning among opposing options in the light of a variety of objectives to be met. The calculations are not composite and the ratio scale ranges between 1 to 9 .

\section{SYSTEM ARCHITECTURE}

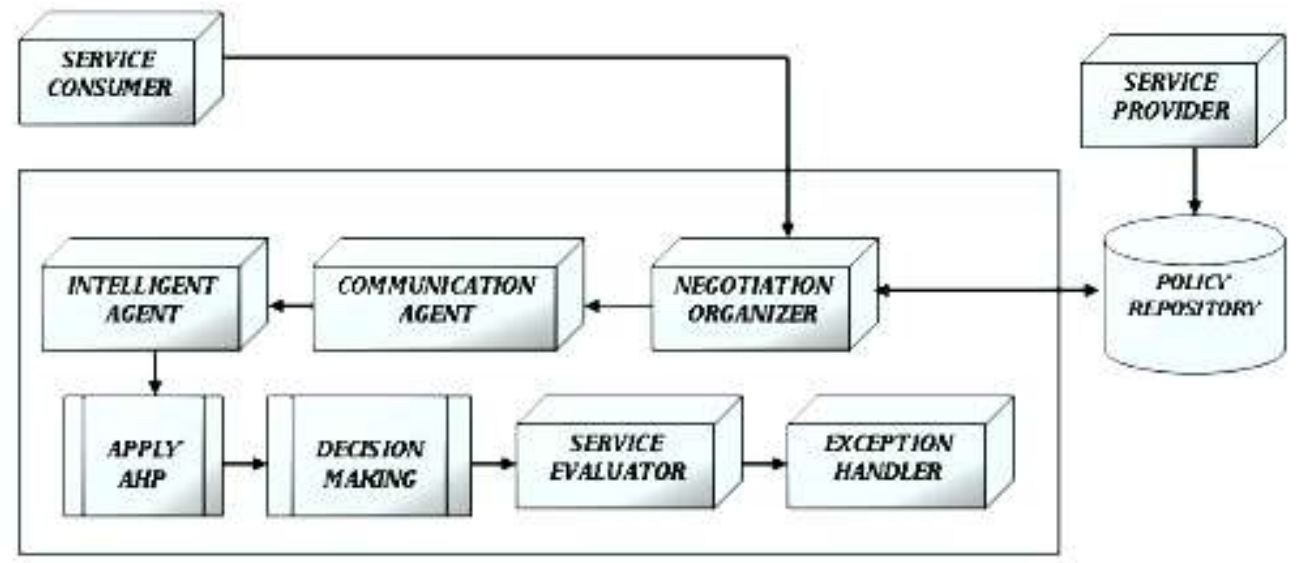

Fig. 2. The Negotiation Organizer Framework

The Negotiation Organizer framework, as shown in Fig. 2. is described in detail below. The service consumer can approach SLA negotiation organizer and request for the service negotiation by giving their own policy. The NO will demand the service provider for their policy if it is not accessible in the policy database. The parties concerned in negotiation can also send the updated policy to the NO. An SLA is an consideration among the service contributor and the service purchaser about the guarantees of delivered services. It describes regular understandings and position of a service between the two parties. The SLA model may consist of the parties concerned in the negotiation, time period over which the SLA is legal, level of services that both the parties consent on, penalties for not congregating the specified service, requirement of what is not roofed in SLA, and so on. The Service level objectives may include service ease of use, customer response time, service response time, service outage resolution time etc. The communication agent then establishes the negotiation linkage between the service provider and service consumer and invokes the intelligent agent .

The intelligent agent $(\mathrm{IA})$ is in charge for conducting the negotiation locally between the service consumer and service provider. The IA gears Analytic Hierarchy Process(AHP) by applying the multi-criteria decision making approach in which the factors are set in hierarchic composition. This type of decision making will ask for the preference from the service purchaser based on the choices included, then the comparison matrix is constructed and the percentage is evaluated for each choices. Likewise the sub-choices is also evaluated and finally the values are substituted in the selected alternative in order to spot out the efficient service. The exception handling and service evaluation process are carried out in the background during the ongoing decision making process by the service evaluator and exception handler component.

\section{AHP AN EFFICIENT DECISION MAKER IN SERVICE NEGOTIATION}

Analytic hierarchy process is very helpful in decision making and hence we applied for service negotiation in web service. Service negotiation ensures the plane rapport between the parties concerned in it. AHP is computed based on the choices gathered from the service consumer. The tactics for solving the problem using AHP consist of three steps: creating hierarchies, precedence evaluation, system stability. The algorithm for AHP is given below:

\section{Function ServiceNegotiation_AHP}

for level:= 1 to $1-1$ do

first_choice:=get the number of choices and sub_choices for the web service at current level

sub_choice $[i]:=$ number of choices and sub_choices for the web service at (level +1$)^{\text {th }}$ level or number of alternatives if level is I- 1 for choice

for $i:=1$ to first_choice do

$\mathrm{j}:=$ sub_choice[i]

// number of sub_choice[i] for first_choice $i$

// pwcm[i] represents pairwise comparison matrix for first_choice $i$

$/ /$ pwcm[i] is of dimension $j \times j$

read pwcm[i] for first_choice $i$ containing paired comparison of $j$ sub_choice

end for $i$ 
for $\mathrm{i}:=1$ to first_choice

calculate the local precedence of the sub_choice of first_choices $\mathrm{i}$

compute the global precedence of the sub_choice by multiplying the local precedence with the global precedence of first_choice i

end for $i$

end for level

$\mathrm{a}:=$ number of alternative

for $\mathrm{i}:=1$ to $\mathrm{a}$ do

ranking $[i]:=$ sum of global precedence of alternative i under different covering criteria

end for $i$

efficient_alternative := choose alternative with the premier ranking rate

return efficient_alternative

end function ServiceNegotiation_AHP

\subsection{Working Model Of AHP}

AHP model is based on receiving the first choices from the service consumer. Both the non-functional(quality parameters) and functional Qos are considered in our project. In the beginning the number of choices and sub_choices are read. Then based on this, it computes the number of pairwise comparison to be done. With this pairwise comparison the matrix is constructed for the choices and sub_choices. By computing the matrix the percentage values are premeditated for both the choices and sub_choices and it is substituted in the alternatives choosen. The premier ranking alternative is selected and delivered as the efficient service to the consumer. The working model of AHP is presented below using three choices and sub_choices.

$\mathrm{n}=$ number of choices and sub_choices are examined

Read the choice : $\left(\mathrm{C}_{\mathrm{i}}, \mathrm{C}_{\mathrm{j}}, \mathrm{C}_{\mathrm{k}}\right)$

Read the sub_choice : $\left\{\begin{array}{ccc}S_{i 1} & S_{j 1} & S_{k 1} \\ S_{i 2} & S_{j 2} & S_{k 2} \\ S_{i 3} & S_{j 3} & S_{k 3}\end{array}\right\}$

Comparison Formula: $\left(\left(n^{*} n\right)-n\right) / 2$

Pairwise Comparison of the Choices:

Compare $\mathrm{C}_{\mathrm{i}}$ with $\mathrm{C}_{\mathrm{j}}$ : $\mathrm{W}_{\mathrm{i}}$

Compare $\mathrm{C}_{\mathrm{j}}$ with $\mathrm{C}_{\mathrm{k}}$ : $\mathrm{W}_{\mathrm{j}}$

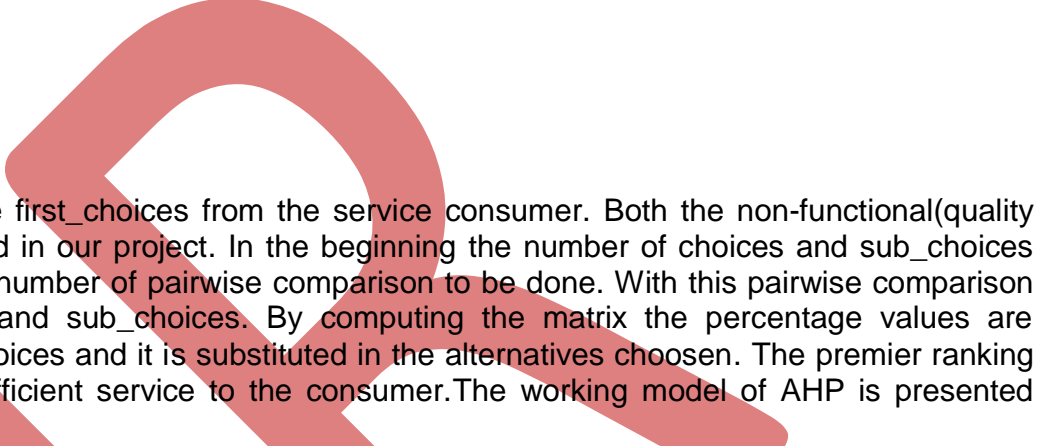

Compare $\mathrm{C}_{\mathrm{k}}$ with $\mathrm{C}_{\mathrm{k}}: \mathrm{W}_{\mathrm{k}}$

\section{Comparison Matrix:}

$C_{i} \quad\left[\begin{array}{ccc}1 & C_{j} & C_{k} \\ C_{k} & W_{i} & W_{j} \\ 1 / W_{i} & 1 & W_{k} \\ 1 / W_{j} & 1 / W_{k} & 1\end{array}\right]$

\section{B. Determine percentage of the Choices:}

\section{Step1: Square the Comparison Matrix}




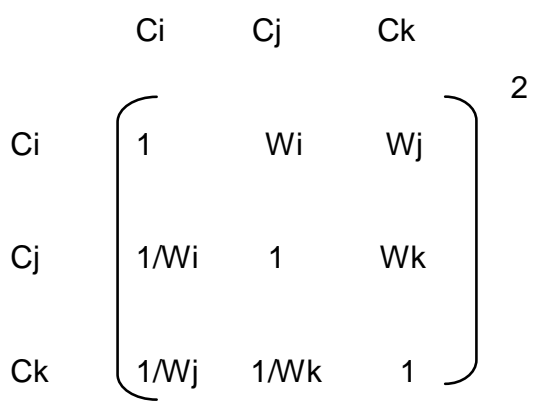

Step2: Find the row sum of the matrix

$$
\begin{aligned}
& \mathrm{X}=[\mathrm{Ci}][\mathrm{Ci}]+[\mathrm{Ci}][\mathrm{Cj}]+[\mathrm{Ci}][\mathrm{Ck}] \\
& \mathrm{Y}=[\mathrm{Cj}][\mathrm{Ci}]+[\mathrm{Cj}][\mathrm{Cj}]+[\mathrm{Cj}][\mathrm{Ck}] \\
& \mathrm{Z}=[\mathrm{Ck}][\mathrm{Ci}]+[\mathrm{Ck}][\mathrm{Cj}]+[\mathrm{Ck}][\mathrm{Ck}]
\end{aligned}
$$

\section{Step 3: Identify the normalized row sums}

Result $=X+Y+Z$

$\mathrm{Ci}=\mathrm{X} /$ Result $; \mathrm{Cj}=\mathrm{Y} /$ Result $; \mathrm{Ck}=\mathrm{Z} /$ Result

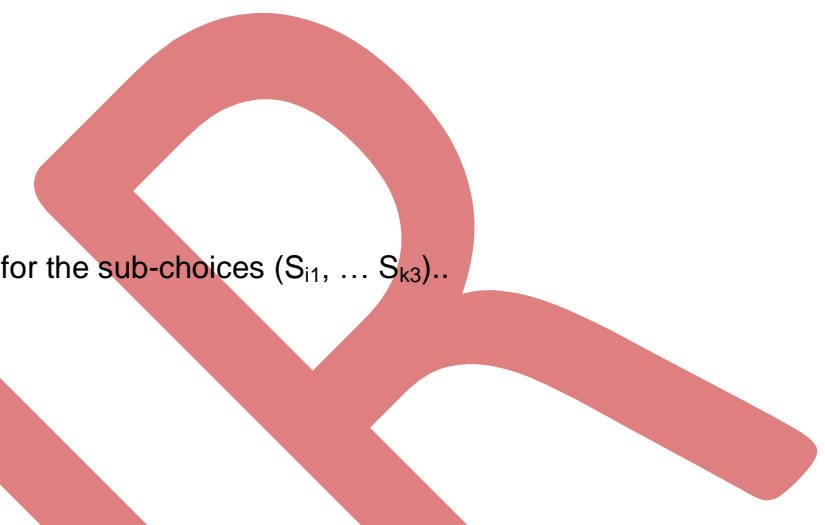

$\mathrm{Ak}=\mathrm{Ck}+\mathrm{S}_{\mathrm{i} 3}+\mathrm{S}_{\mathrm{j}}$

The computed values are substituted in the alternative $\left(A_{i}, A_{j}, A_{k}\right)$ in the order to determine the efficient service.

\section{CONCLUSION}

In this paper, we scrutinize and devise a SLA negotiation system which is based on related work and research set. This paper reveals a formal contract between two parties (i.e) service customer and service donor. Quality of Service should be based on Customer satisfaction. During negotiation process the negotiation broker allow negotiation parties to provide feedback to their agents. In existing system a mathematical policy-mapping model, an adaptive algorithm, Timebased decision system and an intelligent negotiation tactic selection algorithm are used. The time based decision function consists of exponential, polynomial, and sigmoid functions and they are calculated.The service requested by the customer can be offered in short period of time can be done by using time-based decision system. In existing system three different time based decision functions, namely, the exponential, polynomial, and sigmoid functions are implemented. A utilityfunction-based cost-benefit model is used to measure consumer satisfaction for a negotiation offer. Using all these mathematical functions the service requested by the consumer can be offered in short period of time. In our proposed system ,during the negotiation between the service provider and the service consumer, Analytic Hierarchy Process(AHP) is applied so that the best service can be evaluated using certain criteria, sub-criteria and alternatives in short period of time and transferred to the requested consumer after the negotiation in completed. Analytic Hierarchy Process(AHP) is an multi-criteria decision making system. The Analytic Hierarchy Process (AHP) is a hypothesis of capacity through pair-wise comparisons and relies on the judgements of adept to originate priority dimensions. In AHP information is festering into a hierarchy of criteria, sub-criteria and alternatives. Information is then combined to conclude relative ranking of alternatives. Finally a better service has been offered to the customer within short period of time.

\section{FUTURE WORK}

We have done investigation more on service negotiation and Analytic Hierarchy Process. Service negotiation is based on contract between service customer and service donor. In concerning Analytic Hierarchy Process numerous decisions are taken from multiple service. In this paper, algorithm describes efficiency and time maintenance. The AHP also move toward the computation of a consistency ratio to aid judgment makers verify if their pairwise comparisons are consistent. Bilateral bargaining with the Negotiation Organizer(NO) is performed in our current work. In this regard, it can also be experimented with other types of negotiation protocol such as different types of bidding. The NO is a trusted broker middleware because the negotiating parties have to confide their business policies with the NO to outsource the task of SLA negotiation. NO with trust models can also be implemented to establish better trust relationships. In future ,the Negotiation Organizer framework can also be extensive to support multilateral negotiation to apply it to grid computing and parallelize negotiation with multiple providers based on Analytic Hierarchy Process(AHP).

\section{REFERENCES}


[1] Siddiqui.Z, Abdullah.A.H, Khan.M.K, "Qualified Analysis b/w ESB(s) Using Analytical Hierarchy Process (AHP) Method ",International Conference. Intelligent Systems Modelling and Simulation (ISMS) 2011.

[2] Sajid Ibrahim Hashmi, Rafiqul Haque, Eric Schmieders, and Ita Richardson, "Negotiation towards Service Level Agreements: A Life Cycle Based Approach", IEEE, 2011.

[3] Wenliang Chen, Wenbao Jiang, "Analysis and Design of an Adaptive Automated Trust Negotiation System", International Conference on Mechatronic Science, Electric Engineering and Computer 2011.

[4] Elarbi Badidi, "A Framework for Brokered Service Level Agreements in SOA Environments”, IEEE,2011.

[5] Frank Schulz, "Decision Support for Business-related Design of Service Level Agreements", IEEE, 2011.

[6] Minjie Bian, Jiaoxiong Xia, Jun Xu , "Database preprocessing with AHP”, International Conference. Fuzzy Systems and Knowledge Discovery (FSKD), Vol.6, 2010.

[7] Shaoxu Guo, Wenbao jiang, "An Adaptive Automated trust negotiation model and Algorithm", International Conference on Communications and Intelligence Information Security,2010.

[8] Chalouf.M.A, Krief,F, "Service level negotiation in ubiquitous environments", IEEE. Computers and Communications, 2009.

[9] Jianyong Liu, Ling Li, Chengqun Fu, Zhongjun Wu, "A Multiple Criteria Decision Making Model Based on DEA/AR with AHP Preference Cone", Intelligent Systems and Applications, 2009.

[10] Patankar.V, Hewett. R, "Automated Negotiations in Web Service Procurement", Third International Conference. Internet and Web Applications and Services, 2008.

[11] Vahidov.R, Neumann.D, "Situated Decision Support for Managing Service Level Agreement Negotiations", International Conference on System Sciences, 2008

[12] Chunhao.Li, Yonghe Sun, Yanhui Jia "An improved ranking approach to AHP alternatives based on variable weights", pp. 8255 - 8260, 2008.

[13] Liguo Fan, Feng Zuo ,"Research on Multi-Attribute Decision-Making Method Based on AHP and Outranking Relation", Power Electronics and Intelligent Transportation System, 2008.

[14] Guo.P, Tanaka.H, "Decision-making with interval probabilities", IEEE International Conference, Systems, Man and Cybernetics, 2008.

[15] Loftus.C, Sherratt.E, Demestichas.P," Engineering for quality of service", TINA. Global Convergence of Telecommunication and Distributed Object Computing, 1997.

[16] A. Anderson, "An Introduction to the Web Services PolicyLanguage (WSPL)," Proc. Fifth IEEE Int'I Workshop Policies for Distributed Systems and Networks, pp. 189-192, 2004.

[17] M. Comuzzi and B. Pernici, "An Architecture for Flexible WebService QoS Negotiation," Proc. IEEE Int'I Enterprise Distributed Object Computing (EDOC) Conf., pp. 70-82, 2005.

[18] Lewis, G.A., Morris, E., Simanta, S., Wrage, L., "Effects of service-oriented architecture on software development lifecycle activities", Software Process: Improvement and Practice 13(2),135-144 (2008).

[19] Lock, R.; , "Automated Negotiation for Service Contracts,"Computer Software and Applications Conference, 2006.COMPSAC '06. 30th Annual International , vol,2, no., pp: 127-134.

[20] Chao, K.-M.; Younas, M.; Anane, R.; Tsai, C.-F.; Soo, V.-W.; ,"Degree of satisfaction in agent negotiation," ECommerce, 2003.CEC 2003. IEEE International Conference on , vol., no., pp: 68-75.

[21] A. Andrieux, K. Czajkowski, A. Dan, K. Keahey, H. Ludwig, T. Nakata,et al.., "Web Services Agreement Specification (WS-Agreement)"http://www.ogf.org/documents/GFD.107.pdf, 2007.

[22] A.Thirumaran, P.Dhavachelvan, S.Abarna, S.Sheela "Parallel Analytic Hierarchy Process for Web Service discovery and composition ", Conference Publication, pp.456-461,2011.

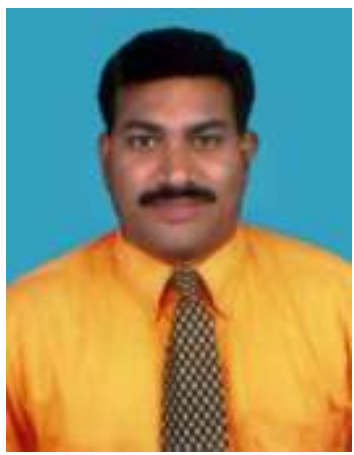

Mr. R. Raju (Research Scholar at Bharathiyar University, Coimbatore), Associate Prof. and Department Head, Information Technology, Sri Manakula Vinayagar Engineering College, Pondicherry, India. 


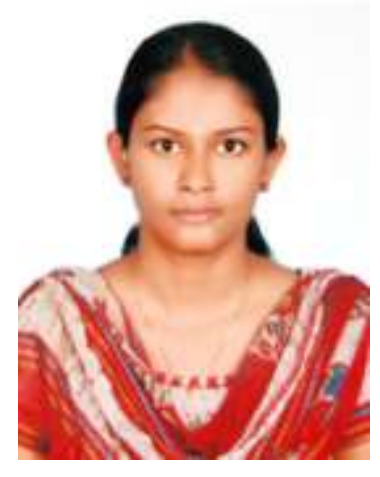

Ms. D.Dhivya, Final Year B. Tech Student, Department of Information Technology, Sri Manakula Vinayagar Engineering College, Pondicherry, India

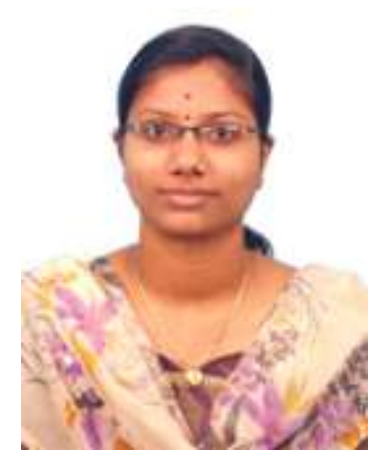

Ms. R.Saranya, Final Year B. Tech Student, Department of Information Technology, Sri Manakula Vinayagar Engineering College, Pondicherry, India

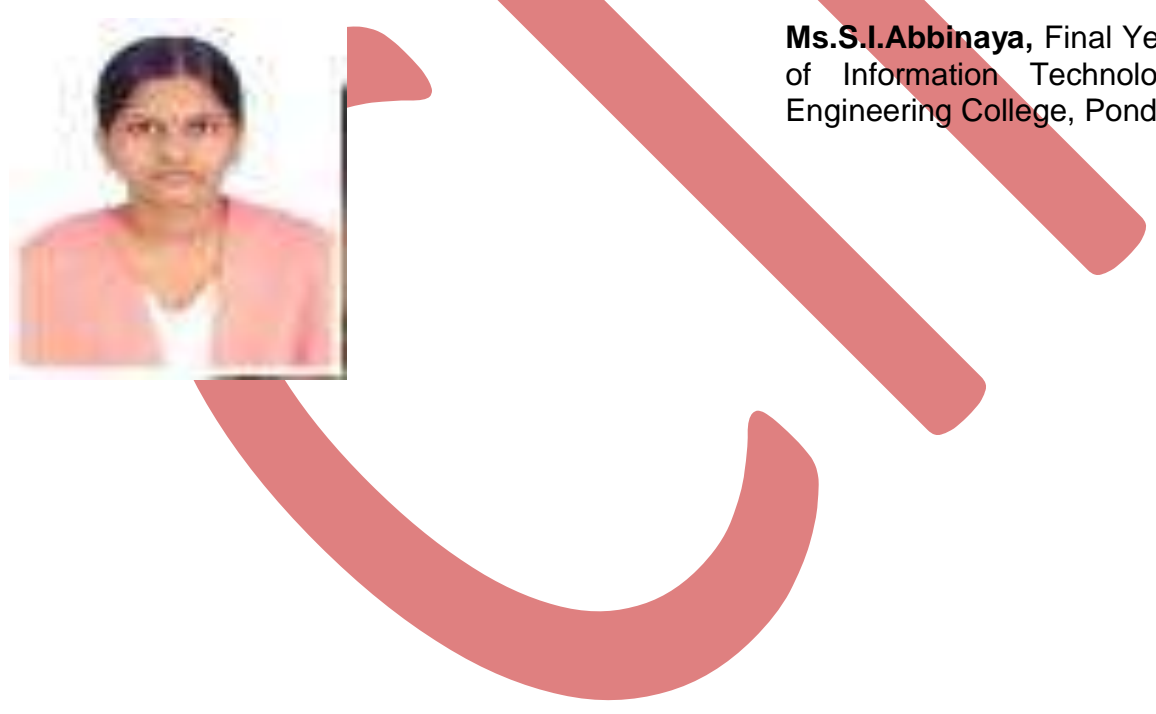

